\title{
Framing the relationship between people and nature in the context of European conservation
}

\author{
John D. C. Linnell, ${ }^{*}$ Petra Kaczensky, $†$ Ulrich Wotschikowsky, $\ddagger$ Nicolas Lescureux, $§$ \\ and Luigi Boitani $\uparrow$ \\ *Norwegian Institute for Nature Research, P.O. Box 5685 Slupen, NO-7485 Trondheim, Norway, email john.linnell@nina.no \\ †Research Institute of Wildlife Ecology, Vetmeduni Vienna, Savoyenstrasse 1, A-1160 Vienna, Austria \\ $\ddagger$ Deutingerstraße 15, D-82487, Oberammergau, Germany \\ §Center for Functional and Evolutionary Ecology (UMR 5175 CNRS), 1919, route de Mende F-34293, Montpellier, France \\ ๆBiology and Biotechnologies, University of Rome La Sapienza, viale Università 32 I-00185, Rome, Italy
}

\begin{abstract}
A key controversy in conservation is the framing of the relationship between people and nature. The extent to which the realms of nature and human culture are viewed as separate (dualistic view) or integrated is often discussed in the social sciences. To explore bow this relationship is represented in the practice of conservation in Europe, we considered examples of cultural landscapes, wildlife (red deer, reindeer, borses), and protected area management. We found little support, for a dualistic worldview, where people and nature are regarded as separate in the traditional practice of conservation in Europe. The borders between nature and culture, wild and domestic, public land and private land, and between protected areas and the wider landscape were blurred and dynamic. The institutionalized (in practice and legislation) view is of an interactive mutualistic system in which bumans and nature share the whole landscape. However, more dualistic ideals, such as wilderness and rewilding that are challenging established practices are expanding. In the context of modern day Europe, wilderness conservation and rewilding are not valid for the whole landscape, although it is possible to integrate some areas of low-intervention management into a wider matrix. A precondition for success is to recognize and plan for a plurality of values concerning the most valid approaches to conservation and to plan for this plurality at the landscape scale.
\end{abstract}

Keywords: cultural landscape, dualism, Europe, protected area, red deer, wild horses, wilderness

Enmarcando la Relación entre las Personas y la Naturaleza en el Contexto de la Conservación en Europa

Resumen: Una controversia clave en la conservación es el marco de la relación entre las personas y la naturaleza. En las ciencias sociales se discute con frecuencia el alcance al cual los reinos de la naturaleza y la cultura humana son vistos como separados (visión dualista) o íntegros. Para explorar cómo se representa esta relación en la práctica de la conservación en Europa consideramos ejemplos de paisajes culturales, vida silvestre (ciervos rojos, renos, caballos) y manejo de áreas protegidas. Encontramos poco apoyo, para una visión dual global, en donde las personas y la naturaleza son vistos como separados en la práctica tradicional de la conservación en Europa. Las fronteras entre la naturaleza y la cultura, lo silvestre y lo doméstico, el suelo público y el suelo privado, y entre las áreas protegidas y el terreno en conjunto, fueron dinámicas y borrosas. La visión institucionalizada (en la práctica y en la legislación) es de un sistema mutualista interactivo en el cual los bumanos y la naturaleza comparten todo el terreno. Sin embargo, se están expandiendo más ideales dualistas, como la naturaleza y la reintroducción, los cuales están obstaculizando a las prácticas establecidas. En el contexto de la Europa contemporánea, la conservación de la naturaleza y la reintroducción no son válidas para todo el terreno, aunque es posible integrar algunas áreas de manejo de baja intervención a una matriz más amplia. Un prerrequisito para el éxito es reconocer y planear una pluralidad de valores con respecto a las estrategias de conservación en la escala de paisaje. 
Palabras Clave: área protegida, caballos silvestres, ciervo rojo, dualismo, Europa, naturaleza, paisaje cultural

\section{Introduction}

Although there is widespread political and societal support for biodiversity conservation in general, there are considerable disagreements about how to implement it. On one level, these disagreements are about the utility of different strategies (e.g., land sparing vs. land sharing [Phalan et al. 2011]). Other debates concern the benefits of fencing protected areas (Watson 2013) and of ecological networks (Boitani et al. 2007). A deeper level of disagreement concerns the moral and philosophical aspects of biodiversity conservation. Central concerns include the appropriate ways in which humans should interact with nature (Mace 2014). Illustrative of these concerns are debates about conserving wilderness versus managed landscapes, about hunting (Treves 2009), and about how to address human-wildlife conflicts (Redpath et al. 2013). Controversies surrounding so-called new conservation (Marvier \& Kareiva 2014), Pleistocene rewilding (Rubenstein et al. 2006), and emerging concepts such as novel ecosystems (Hobbs et al. 2013) illustrate the challenges of separating debates about practice from those about principle. The way the human-nature relationship has been framed in conservation biology falls into 4 phases: nature for itself, nature despite people, nature for people, and people and nature (Mace 2014), all of which are currently competing.

These discussions are far from academic because the way that biodiversity conservation is justified and conducted is likely to be instrumental in shaping the way decision makers, wider society, and especially rural people, who will have to live with the consequences, react to the conservation agenda. There has been an explosion in literature on ecological and environmental ethics in recent years, but little has trickled down into conservation practice, and these disciplines remain distant from the reality of people sharing their landscapes with biodiversity. Although human-dimension studies help conservation professionals understand of how people relate to biodiversity and its conservation, they rarely explore the socio-cultural norms that underlie some of the fundamental conservation controversies.

We used the lenses of anthropology and science studies to examine how the practice of conservation in Europe has been conducted to shed light on the underlying ontology and cosmology of European biodiversity conservation, especially with respect to the way interactions between people and nature are managed and framed. We studied a selection of examples from wildlife management, protected area management, and land management that represent the operational frameworks within which biodiversity has been managed for decades. These examples reflect the day to day practice of conservation, rather than the academic debate around it.

\section{Dichotomies between Nature and Culture}

In much of modern occidental science, traditional disciplinary borders are based on an assumed dichotomy between nature and culture (Descola \& Palsson 1996; Descola 2013). In this dualistic framework, animals, plants, and the environment are believed to obey the universal laws of nature studied by natural scientists. Humans themselves are considered dual beings. Their biological parts are studied by natural scientists, and their social and cultural parts are studied by the humanities and social scientists (Ingold 2000). A consequence of dualism concerning the ontology of nature and culture is a more specific dichotomy between natural processes and human processes and between the wild and the domestic (Descola 2004).

This conceptualized nature-culture dichotomy has been widely criticized (Cronon 1995). First, the anthropological and geography literature illustrates that the dualistic paradigm is not universal (Ellen \& Fukui 1996; Ingold 2000; Castree \& MacMillan 2001; Descola 2013). Second, the concept of humans as unique dual beings with biological and cultural parts is challenged by recent research in ethology, cognitive science, and ecological psychology (Bekoff 2003). Furthermore, it appears most cultural learning and humans tasks are not represented or communicated in learning situations but are rather the result of an individual or social engagement with the natural and cultural world in which they live (Ingold 2000). Finally, the discipline of science studies in particular has exposed the contradictions between the existing dichotomy in the science discourse and the practices of scientists (Haraway 2008), generating a "proliferation of hybrids" between nature and culture (Latour 1993).

The dualistic model is formally believed to be a widespread property of occidental culture and society. However, based on our collective experience in social and natural sciences research in Europe, engagement in wildlife management and biodiversity conservation, and work at the science-policy interface, we believe that the dichotomy is not evident in conservation practices and that there is a proliferation of conceptual hybrids (sensu Latour 1993) and thus rather blurry borders between nature and culture. 


\section{Deliberate Conservation of the Artificial in Cultural Landscapes}

One of the most idiosyncratic aspects of European conservation concerns a range of habitat types (e.g., grasslands, meadows, moorlands, and heaths [Isselstein et al. 2005; Garcia et al. 2013]) created and maintained by centuries of human activity, including fire, livestock grazing, and mowing. Despite their creation through human activity, European legislation (Bern Convention and the Habitats Directive) mandate their conservation. This legislation often prohibits natural succession following land-use abandonment (Queiroz et al. 2014). Of the habitat listed in the Habitats Directive, an estimated 63 of 231 depend on some form of low intensity agricultural intervention (Halada et al. 2011). A whole school of ecological expertise has developed around maintaining these areas, applying for example the targeted grazing of different combinations of domestic species or carefully timed physical interventions.

The motivations for conserving these early successional habitats are twofold. First, they are associated with high species diversity, including charismatic species such as flowers and butterflies. Second, these landscapes are associated with high aesthetic and cultural heritage values. Landscape preference studies show that people clearly prefer these open, diverse landscapes. There is an increasing movement to recognize the cultural landscapes of Europe as monuments to the work of previous generations (Agnoletti 2014). This view is formalized in legislation such as the European Landscape Convention (Jones \& Stenseke 2011). To many rural people, these landscapes and the agricultural activities with which they are associated are important elements of their identity and sense of place. Consequently, there is widespread rural support for their conservation.

The desire to use constant intervention to maintain a specific desired form of nature was uncontroversial in Europe for many decades. However, the recent emergence of a European version of wilderness conservation (Martin et al. 2008) and rewilding (Navarro \& Pereira 2012) is challenging this view. Some supporters of these new ideologies are happy to embrace the loss of early successional habitats, whereas others seek to reconcile the two issues. One line of argument is that these habitats are natural and only need to be maintained by artificial means because of the Holocene extinction of mega-herbivores (Vera 2000). The result has been attempts to rewild some landscapes with a range of extant wild and surrogate herbivore species in the hope that particular habitat types can be maintained through processes that exclude human agency. However, there is widespread scientific uncertainty about the extent of these habitats preceding agriculture (Birks 2005) and the ability of these herbivores to maintain them without fire and cutting (Kirby 2009; Kerley et al. 2012). Other factors such as climate change during the Holocene are also likely to have been important. The goals and means of these approaches are also controversial. Many rural people disapprove of the removal of human agency from the landscape because it has been the interaction between people and nature that has given the landscape its value, not just the landscape itself (Schwartz 2005; Bauer et al. 2009). There are also concerns about animal welfare and legal issues regarding the use of domestic animals as ecological surrogates for extinct species (e.g., Lorimer \& Driessen 2013). The cultural landscape example illustrates clearly how many Europeans have not previously seen sharp or consistent separations between wild and domestic or nature and culture.

\section{The Case of European Wild Horses}

Europe was once home to wild horses (Equus ferus) that roamed across the Pleistocene steppes and persisted well into the Holocene (Bendrey 2012). The extent to which E. ferus genes are incorporated in European domestic horses is controversial, especially because of discussions about the putative relationship between $E$. ferus and the free-living tarpan that persisted into the late 19th century. Irrespective of the details of historical processes the current situation is that $E$. ferus is extinct, apart from some potential, but unproven, genetic representation in domestic breeds.

Domestic horses have long been central agents in habitat conservation actions in Europe. In most cases, domestic breeds with a local cultural value have been used. Originally, these horses were named after the location they grazed in, for example, Camargue horses or New Forest ponies. This explicitly recognized their domesticity and their cultural value. However, in recent years the rhetoric around this type of grazing has changed. This form of controlled grazing is increasingly referred to as "natural grazing" in the technical literature (Hodder \& Bullock 2009). Recently, there has been an increase in the use of certain breeds such as Konik horses that have putative links to tarpans or Heck horses that have been back-bred to resemble tarpans. Although it is recognized that these breeds are domestic surrogates for E. ferus, they are increasingly referred to as wild (Linnartz \& Meissner 2014), despite active management of these horses (e.g., supplemental feeding, population regulation), their restriction to fenced areas, and the absence of predation. In contrast, Europe has many populations of horses kept for primarily agricultural purposes under free-ranging conditions that are rarely called wild, despite their being exposed to stronger environmental pressures, including predation, and having far greater freedom of movement (Lopez-Bao et al. 2013).

This example reflects the way Europeans use carefully controlled grazing to maintain cultural landscapes while simultaneously calling the process natural. It also shows 
how readily people accept the transition of a domestic species to a wild state.

\section{The Case of Red Deer}

Red deer (Cervus elapbus) are among the most widespread of wild herbivores in Europe. Throughout their range, they have been a highly valued game species for millennia and have been subject to intensive management for centuries (Apollonio et al. 2010). In some countries (e.g., Norway), red deer roam free; occupy all areas they can colonize; and are not subject to systematic winter feeding (although ad hoc feeding occurs in some areas). These red deer are exposed to selective pressures ranging from predation, to harsh weather, to food limitation. However, red deer in Norway are the exception. Germany, for example, enforces a clear zoning policy (enforced through hunting) that prevents red deer from colonizing most of the country. In most European countries, red deer (like many other game species) are subject to high rates of supplementary feeding, especially during winter. In Austria, Germany, Slovakia, Czech Republic, Croatia, and Romania provision of winter fodder is a legal obligation for hunters, whereas in other countries it is voluntary. Winter feeding is intended to increase population density and prevent mortality and to prevent red deer from over-wintering in areas where human-deer conflicts might be high (e.g., where deer may damage commercially valuable trees). The strategy has partly evolved as a response to the loss of traditional winter habitats to agriculture and urbanization. Feeding has a dramatic impact on demographics and space use and involves the provision of hay, root crops, or pellets at specific sites and the planting of special crops on fields set aside for the sole use of deer. Only a few jurisdictions (the Netherlands, some Swiss cantons) currently prohibit winter feeding.

In parts of the German and Austrian Alps, the practice has evolved further to include winter enclosures (55 in Bavaria and 155 in Austria). In this system, red deer are induced to return to a fenced area where food is provided during autumn and then enclosed for the winter and provided with food. Animals that do not enter the enclosures are often shot. The thought is that the confinement of animals prevents them from damaging surrounding forests. Other countries have gone even further to limit movements of red deer. In Spain and Scotland, it is becoming increasingly common to use game fencing (sometimes supported with supplementary feeding) to prevent red deer from moving beyond the borders of specific hunting estates, which permits land managers to intensify management of their own population and prevent any leakage of animals to neighboring properties. In eastern and southeastern Europe (e.g., Serbia, Macedonia, Bulgaria, Greece, Slovakia, Belarus, and Hungary), there is a growing trend to establish fenced hunting grounds. In many respects, these are a modern incarnation of the royal deer parks that were common as far back as the Middle Ages. This widespread manipulation of red deer also extends into protected areas. In a survey of red deer management in European national parks, Gunther and Heurich (2013) found that almost all practiced some form of intervention (feeding, winter enclosure, or hunting).

Red deer are also the most recently domesticated wild herbivore. There are over 10,000 deer farms in operation in Europe. Given red deer management regimes, it is difficult to say under which contexts animals are wild and under which they are domestic. Most countries' management systems dramatically influence the ecology, demography, and space use of their animals, with hunters additionally asserting a strong selection pressure through their focus on trophy males. Combined, these pressures are akin to what occurs during a domestication process (Mysterud 2010). The differences are simply of degree. At the extremes, there are cases of so-called wild red deer that are managed in ways that are indistinguishable from deer that are farmed as domestic animals. Red deer provide an example of the diversity and complexity of ways in which people from different countries interact with wild species.

Red deer populations in Europe are currently far larger and more widespread than they have been for centuries (Linnell \& Zachos 2011), indicating that these management strategies have allowed the species to recover dramatically from late 19th century lows. Furthermore, it provides another example of the low threshold that many segments of society require to call something wild. Alternatively, red deer management can be viewed as an extreme example of the lengths to which people will go to find practical ways to integrate wild species into modern landscapes.

\section{European Protected Areas}

Europe has a diversity of protected-area categories that are designed to protect a wide range of values. One key characteristic of these is the extent to which they are designed to preserve cultural heritage in the form of historical sites, traditional activities, and human-modified landscapes in addition to areas with low degrees of human intervention. Of the 14,727 protected areas in the Natura 2000 network most permit agriculture (69\%), forestry (59\%), livestock grazing (46\%); and hunting, fishing, and gathering activities (53\%) (Tsiafouli et al. 2013). Tsiafouli et al. (2013) conclude that rather than preserving wilderness, the network is mainly "co-managing biologically diverse landscapes in which humans constitute an integral part."

In 2012 J.D.C.L. conducted an internet survey among members of the EUROPARC association (74 of 259 
surveyed protected areas responded). Forty percent of these administrations permitted livestock grazing, 26\% permitted hunting, and $49 \%$ conducted mowing as a strategy to maintain meadows. Even though there was widespread integration of human activities, the protected areas ranked preserving wilderness values and rewilding as key objectives, and maintaining cultural landscapes and heritage values were secondary objectives. This discrepancy is potentially due to two issues. First, it probably reflects a linguistic issue; few European languages have a word for wilderness that is as strict as the term used in the English language scientific literature and that does not either explicitly or implicitly exclude human presence or activity. Also, having lost any reference points in the distant past, many may regard the present state as wilderness. Second, the discrepancy may represent a process of changing values. Ongoing human activity in many protected areas represents a legacy of the past (with their associated socio-economic frames and values), and practice may change slower than values. There is an ongoing movement in European protected areas to reduce the extent of human activity in certain zones so as to permit more natural processes (Coleman \& Aykroyd 2009) or a return to some Edenistic state (Robbins \& Moore 2013). Therefore, respondents to the survey may be reflecting an emerging set of values that are just beginning to influence conservation practices in their protected areas.

The reality is that despite their importance for some species, such as those associated with old-growth forest, minimal intervention zones are currently the exception rather than the rule, and most protected areas are still heavily influenced by human activities, albeit often those of a traditional character and at low intensity. There is a widespread tendency to adopt a very diffuse and smallspatial-scale definition of wilderness. Human activity such as hunting, mowing, and livestock grazing is widespread even among the 13 European Pan-Park sites, which are intended to be premier wilderness sites (based on a 2014 internet survey of the parks' home pages and management plans). Nonintervention is therefore, at best, only practiced in limited zones, such as core areas of protected areas that otherwise generally permit a range of human activities. Most European protected areas are relatively small (EEA 2012), which is a major technical barrier to the reduction of human influence given the mismatch in size between those of the area boundaries and the scales at which ecological processes occur.

European protected areas illustrate that the general approach to their management has not excluded traditional human activities but that this approach is changing.

\section{Inside versus Outside Protected Areas}

European conservation legislation does not often differentiate between areas inside and outside protected areas. For example, the level of species protection afforded by the Bern Convention and the Habitats Directive applies to the entire European area irrespective of its protected status. Furthermore, these laws do not differentiate between public and private land, which is important for conservation (many protected areas are on private land). Widespread use of economic incentives through agri-environmental schemes to foster biodiversity conservation in farmland also indicates that protected and unprotected areas are not differentiated. This reflects a long-standing view that human activity within protected areas complements biodiversity conservation throughout the wider landscape.

\section{European Large Carnivores}

Large carnivore populations have increased dramatically since the mid 20th century. Currently, there are approximately 17,000 bears (Ursus arctos); 12,000 wolves ( $\mathrm{Ca}$ nis lupus); 8,000 Eurasian lynx (Lynx lynx); and 1,000 wolverines (Gulo gulo) in Europe (excluding Russia and Ukraine) (Chapron et al. 2014). Although large carnivores are normally associated with wilderness, in Europe the bulk of their distribution is outside protected areas in multiuse landscapes. This distribution implies their ecology is heavily influenced by human activities. Generally speaking, in central and northern Europe ungulate densities are held artificially high due to supplementary feeding, access to crops, and maintenance of early successional stages in forests, whereas in southern Europe densities are suppressed by poor management of hunting and poaching. All European habitats are heavily modified by agriculture and are fragmented by transport infrastructure and urbanization. In Slovenia, Croatia, Bosnia, Herzegovina, and Romania, bears are fed at feeding stations. Livestock also constitute an important prey for carnivores in some areas, permitting them to occupy regions where they would not otherwise persist (Vos 2000; Mattisson et al. 2011). In several countries, carnivores are subject to hunting or population control. These anthropogenic factors directly affect all trophic levels (predators, prey, habitat) and influence carnivore populations in different ways, alternatively increasing and decreasing carrying capacity and demographic rates. The result is that carnivore demographics are ultimately controlled (directly and indirectly) by humans. The implication is that we cannot expect to see many of the dynamics associated with trophic cascades and top-down regulation of prey with associated knock on effects to habitats and other species that have been claimed for other ecosystems (Terborgh \& Estes 2010).

Although Europe has successfully fostered the recovery of its carnivores, it has not restored (or even tried to) the full set of ecological functions (Ordiz et al. 2013) that would have occurred without human 
presence. However, large carnivores are still part of ecological processes, although the feedback loops are heavily modified by humans.

Large carnivores are often regarded as ultimate symbols of wild nature, although the European experience shows they can survive in very heavily modified and domesticated landscapes (Blanco \& Cortes 2009). Their future in Europe depends on their continued persistence in modified landscapes because protected areas are too small to support many individuals, let alone populations. Carnivores represent an extreme example of the potential for integrating the wild into the domestic and of Europe's efforts to integrate nature and culture in the same space.

\section{Europe as a Biocultural System}

We have shown examples of where nature and culture and the wild and domestic share space and have blurred borders and where species can make transitions between wild and domestic states. These examples are characteristic of a biocultural system (Maffi \& Woodley 2010), where the interaction between nature and culture are pervasive and widely perceived as adding value to the whole. In some ways, the biodiverse cultural landscape is a form of mutualism. Unfortunately, this system has never been well described in any conceptual context. Europe is a very fragmented continent in terms of language and culture, and European conservation has never had a Thoreau or Leopold to articulate its underlying philosophy and practice. Thus, the main approach has been based on a tacit understanding of the underlying principles rather than their explicit formulation. In contrast to Mace's (2014) timeline, it appears the "people and nature" frame was in place long before the "nature for itself" frame appeared in the discourse.

However, discourses associated with wilderness and rewilding (that originated in North America) are now part of European conservation (Martin et al. 2008; Navarro \& Pereira 2012). This is leading to the promotion of a far more dualistic ideal, where humans and their interactions with nature are viewed as "pollution" in an otherwise "pure" nature (Knight 2000; Milton 2000; Robbins \& Moore 2013). Although these new discourses clearly resonate with many conservation professionals and environmentalists, they are also major sources of conflict for many rural stakeholders (Schwartz 2005; Bauer et al. 2009).

Various strands of modern day conservation science are being used to legitimize both approaches. The recent papers on trophic cascades (Terborgh \& Estes 2010) and Pleistocene rewilding (Donlan et al. 2006) are important to the advocates of wilderness (dualistic) values. In contrast, there are emerging discourses that mirror the classical European approach (nondualistic) within frameworks such as "novel landscapes" (Hobbs et al. 2013), "coupled social-ecological systems" (Liu et al. 2007), "land sharing" (Phalan et al. 2011), and ecosystem services. These discourses are also spreading into the popular science literature (e.g., Marris 2011; Monbiot 2013).

Dualistic and nondualistic approaches favor different aspects of biodiversity conservation and come with their own sets of challenges. Considering the needs society has for a diversity of ecosystem services (food, fuel, water) and space (living space, transport), it is clear that wilderness does not offer a general model for the whole landscape. This does not mean there is no room for areas of minimum intervention in protected areas or that species and area management cannot lessen controls so as to allow ecological processes to take a more natural course. The majority of the landscape will inevitably remain under human influence, but as has been seen this can include a great deal of biodiversity. However, a nondualistic approach of land sharing is associated with controversies and conflicts. A classic example is the recovery of predators in areas from which they had been exterminated (Redpath et al. 2013). All strategies will likely require consideration of diverse stakeholder perspectives and establishment of appropriate governance structures that are effective, fair, open, and regarded as legitimate.

\section{Wider Contexts}

There are parallels between European conservation and conservation on other continents, where wildlife conservation occurs outside protected areas, human activity occurs inside protected areas, and many practices blur the distinctions between wild and domestic and nature and culture. The origin of ideas surrounding biocultural systems comes from non-European contexts (Maffi \& Woodley 2010). We believe a special characteristic of European conservation is the widespread technical, social, and legislative support for a nondualistic approach within a first world context. This may also reflect that modern day Europeans are technically indigenous to their continent and have therefore had a longer period to develop a nuanced association with their environment. Although never explicitly articulated as a philosophical approach, for many decades research and administrative effort has institutionalized nondualistic practices. In contrast, other continents have to a far greater extent built institutions that are based on a dualistic view (Ghosal et al. 2013).

The widespread existence and viability of nondualistic practices indicates that the idea of a strict dichotomy between nature and culture, or wild and domestic, has not translated into conservation practices in Europe. It may be hypothesized that the dualistic approach, which was once the property of elite discourses, is spreading into general conservation discourses but is not being applied. It could also be that a dualistic approach is a 
property of modernity, which generates contradictions between discourses and practices (Latour 2004). It is time to complement academic cosmology with a mapping of the diverse cosmologies of the public. The result could be conservation with less conflict.

Based on our findings, there are key issues that need to be considered in planning for the future of biodiversity conservation in Europe. First, there is a need to consider the deep, complex, and ancient intertwining of nature and culture in Europe. Ignoring this, by advocating a form of biodiversity conservation that excludes people, will increase conflicts associated with how the various publics react to the conservation agenda. Second, there is a need to accept that the borders between nature and culture and wild and domestic are blurry, diverse, and dynamic. This implies that approaches will have to be adaptive, vary in time and space, and pragmatic. Attempts to impose a simplistic and universal approach based on the prominence of the ideal of wilderness will not succeed. Third, there is a need to accept that the traditional European model is changing. There is growing public pressure to conserve relatively wild areas (e.g., roadless areas [Selva et al. 2011]) and recreate wilderness, or at least decrease intervention in some protected areas (Coleman \& Aykroyd 2009). These changes in the direction of enhanced dualism are in contrast to other processes such as the recovery of large carnivores and large herbivores in human-dominated landscapes that are pushing the limits of nondualism. Although the balancing of these competing issues will always result in conflicts, we believe conservation can succeed if there is widespread acceptance of the legitimacy of multiple values and the adaptive use of large-scale land-use planning tools to devise landscapescale strategies that intersperse areas of low-intervention in a matrix of biodiversity rich multiuse landscapes.

\section{Acknowledgments}

J.D.C.L. was supported by the Research Council of Norway and the Norwegian Environmental Agency. N.L. was supported by the Research Council of Norway and a Marie Curie mobility grant from the EU's FP7 Program. J. Alleau provided great assistance with the survey of EUROPARC members. We acknowledge the many discussions with colleagues that have helped us focus these ideas.

\section{Literature Cited}

Agnoletti M. 2014. Rural landscape, nature conservation and culture: some notes on research trends and management approaches from a (southern) European perspective. Landscape and Urban Planning 126:66-73.

Apollonio M, Andersen R, Putman R. 2010. European ungulates: and their management in the 21st century. Cambridge University Press, Cambridge, United Kingdom.
Bauer N, Wallner A, Hunziker M. 2009. The change of European landscapes: human-nature relationships, public attitudes towards rewilding, and the implications for landscape management in Switzerland. Journal of Environmental Management 90:2910-2920.

Bekoff M. 2003. Consciousness and self in animals: some reflections. Zygon 38:229-245.

Bendrey R. 2012. From wild horses to domestic horses: a European perspective. World Archaeology 44:135-157.

Birks HJB. 2005. Mind the gap: How open were European primeval forests? Trends in Ecology \& Evolution 20:154-156.

Blanco JC, Cortes Y. 2009. Ecological and social constraints of wolf recovery in Spain. Pages 41-66 in Musiani M, Boitani L, Paquet PC, editors. A new era for wolves and people: wolf recovery, human attitudes, and policy. University of Calgary Press, Calgary.

Boitani L, Falcucci A, Maiorano L, Rondinini C. 2007. Ecological networks as conceptual frameworks or operational tools in conservation. Conservation Biology 21:1414-1422.

Castree N, MacMillan T. 2001. Dissolving dualisms: actor-networks and the reimagination of nature. Pages 208-224 in Castree N, Braun B, editors. Social nature: theory, practice and politics. Wiley-Blackwell, Oxford.

Chapron G, et al. 2014. Recovery of large carnivores in Europe's modern human-dominated landscapes. Science 346:1517-1519.

Coleman A, Aykroyd T. 2009. Conference proceedings: wild Europe and large natural habitat areas, Prague 2009. Wild Europe. 155 pages.

Cronon W. 1995. Uncommon ground: rethinking the human place in nature. W. W. Norton and Co., New York.

Descola P. 2004. Le sauvage et le domestique. Communications 76:1739.

Descola P. 2013. Beyond nature and culture. University of Chicago Press, Chicago.

Descola P, Pålsson G. 1996. Nature and society: anthropological perspectives. Routledge, London.

Donlan CJ, et al. 2006. Pleistocene rewilding: an optimistic agenda for twenty-first century conservation. The American Naturalist 168:660-681.

EEA. 2012. Protected areas in Europe - an overview. European Environmental Agency Report 5/2012, Copenhagen.

Ellen R, Fukui R. 1996. Redefining nature: ecology, culture and domestication. Berg, Oxford.

García RR, Fraser MD, Celaya R, Ferreira LMM, García U, Osoro K. 2013. Grazing land management and biodiversity in the Atlantic European heathlands: a review. Agroforestry Systems 87:19-43.

Ghosal S, Athreya VR, Linnell JDC, Vedeld PO. 2013. An ontological crisis? A review of large felid conservation in India. Biodiversity and Conservation 22:2665-2681.

Gunther S, Heurich M. 2013. Assessment of the naturalness of the red deer management in Central European national parks. Allgemeine Forst Und Jagdzeitung 184:1-16.

Halada L, Evans D, Romao C, Petersen J-E. 2011. Which habitats of European importance depend on agricultural practices? Biodiversity and Conservation 20:2365-2378.

Haraway DJ. 2008. When species meet. University of Minnesota Press, Minneapolis.

Hobbs RJ, Higgs ES, Hall CM. 2013. Novel ecosystems: intervening in the new ecological world order. Wiley-Blackwell, Oxford.

Hodder KH, Bullock JM. 2009. Really wild? Naturalistic grazing in modern landscapes. British Wildlife 20:37-43.

Ingold T. 2000. The perception of the environment. Essays in livelihood, dwelling and skill. Rutledge, London.

Isselstein J, Hjeangros B, Pavlu V. 2005. Agronomic aspects of biodiversity targeted management of temperate grasslands in Europe - a review. Agronomy Research 3:139-151.

Jones M, Stenseke M. 2011. The European landscape convention: challenges of participation. Springer, Berlin.

Kerley GIH, Kowalczyk R, Cromsigt JPGM. 2012. Conservation implications of the refugee species concept and the European bison: King 
of the forest or refugee in a marginal habitat? Ecography 35:519529.

Kirby KJ. 2009. Policy in or for the wilderness. British Wildlife 20:5962.

Knight J. 2000. Introduction. Pages 1-35 in Knight J, editor. Natural enemies: people-wildlife conflicts in anthropological perspectives. Routledge, London.

Latour B. 1993. We have never been modern. Harvard University Press, Cambridge.

Latour B. 2004. The politics of nature: how to bring science into democracy. Harvard University Press, Cambridge, Massachusetts.

Linnartz L, Meissner R. 2014. Rewilding horses in Europe: background and guidelines - a living document. Rewilding Europe, Nijmegen, The Netherlands.

Linnell JDC, Zachos FE. 2011. Status and distribution patterns of European ungulates: genetics, population history and conservation. Pages 12-53 in Putman R, Apollonio M, Andersen R, editors. Ungulate management in Europe: problems and practices. Cambridge University Press, Cambridge, United Kingdom.

Liu JG, et al. 2007. Complexity of coupled human and natural systems. Science 317:1513-1516.

López-Bao JV, Sazatornil V, Llaneza L, Rodríguez A. 2013. Indirect effects on heathland conservation and wolf persistence of contradictory policies that threaten traditional free-ranging horse husbandry. Conservation Letters 6:448-455.

Lorimer J, Driessen C. 2013. Wild experiments at the Oostvaardersplassen: rethinking environmentalism in the Anthropocene. Transactions of the Institute of British Geographers 39:169-181.

Mace GM. 2014. Whose conservation? Science 345:1558-1560.

Maffi L, Woodley E. 2010. Biocultural diversity conservation: a global source book. Earthscan, London.

Marris E. 2011. Rambunctious garden: saving nature in a post-wild world. Bloomsbury, London.

Martin VG, Kormos CF, Zunnino F, Meyer T, Doerner U, Aykroyd T. 2008. Wilderness momentum in Europe. International Journal of Wilderness 14:34-43.

Marvier M, Kareiva P. 2014. The evidence and values underlying 'new conservation'. Trends in Ecology \& Evolution 29:131-132.

Mattisson J, Odden J, Nilsen EB, Linnell JDC, Persson J, Andren H. 2011. Factors affecting Eurasian lynx kill rates on semi-domestic reindeer in northern Scandinavia: Can ecological research contribute to the development of a fair compensation system? Biological Conservation 144:3009-3017.

Milton K. 2000. Ducks out of water: nature conservation as boundary maintenance. Pages 229-248 in Knight J, editor. Natural enemies. Routledge, New York.
Monbiot G. 2013. Feral. Searching for enchantment on the frontiers of rewilding. Allen Lane, London.

Mysterud A. 2010. Still walking on the wild side? Management actions as steps towards semi-domestication of hunted ungulates. Journal of Animal Ecology 47:920-925.

Navarro LM, Pereira HM. 2012. Rewilding abandoned landscapes in Europe. Ecosystems 15:900-912.

Ordiz A, Bischof R, Swenson JE. 2013. Saving large carnivores, but losing the apex predator? Biological Conservation 168:128133.

Phalan B, Onial M, Balmford A, Green RE. 2011. Reconciling food production and biodiversity conservation: land sharing and land sparing compared. Science 333:1289-1291.

Queiroz C, Beilin R, Folke C, Lindborg R. 2014. Farmland abandonment: Threat or opportunity for biodiversity conservation? A global review. Frontiers in Ecology and the Environment 12:288296.

Redpath SM, et al. 2013. Understanding and managing conservation conflicts. Trends in Ecology \& Evolution 28:100-109.

Robbins P, Moore SA. 2013. Ecological anxiety disorder: diagnosing the politics of the Anthropocene. Cultural Geographies 20:3-19.

Rubenstein DR, Rubenstein DI, Sherman PW, Gavin TA. 2006. Pleistocene park: Does re-wilding North America represent sound conservation for the 21st century? Biological Conservation 132:232238.

Schwartz KZS. 2005. Wild horses in a European wilderness: imagining sustainable development in the post-Communist countryside. Cultural Geographics 12:292-320.

Selva N, Kreft S, Kati V, Schluck M, Jonsson B-G, Mihok B, Okarma H, Ibisch PL. 2011. Roadless and low-traffic areas as conservation targets in Europe. Environmental Management 48:865-877.

Terborgh J, Estes JA. 2010. Trophic cascades: predators, prey, and the changing dynamics of nature. Island Press, London.

Treves A. 2009. Hunting for large carnivore conservation. Journal of Applied Ecology 46:1350-1356.

Tsiafouli MA, Apostolopoulou E, Mazaris AD, Kallimanis AS, Drakou EG, Pantis JD. 2013. Human Activities in Natura 2000 Sites: a highly diversified conservation network. Environmental Management 51:10251033.

Vera FWM. 2000. Grazing ecology and forest history. CABI International, Wallingford.

Vos J. 2000. Food habits and livestock depredation of two Iberian wolf packs (Canis lupus signatus) in the north of Portugal. Journal of Zoology, London 251:457-462.

Watson T. 2013. Fences divide lion conservationists. Nature 503:322323. 